\title{
Construction and reflection of blended teaching mode In 5G Era
}

\author{
Yue $\mathrm{Wu}^{*}$ \\ Teachers College of Qingdao University, Qingdao, Shandong 266071, China.
}

\begin{abstract}
After nearly 30 years of development, blended teaching at home and abroad is becoming the "new normal" of future education. Especially in the context of "Internet plus education", the training of innovative talents and the reform of education and teaching are all calling for mixed teaching.

In China, online education is recognized by more and more teachers and students, online education users grow rapidly, video teaching has become an important means of online education. But up to now, the research of mixed education mode in China is still in the exploratory stage, the mature mixed teaching mode is relatively less, and there are a series of problems, such as cumbersome operation, low response of students and so on.
\end{abstract}

Keywords: Hybrid teaching mode; Nail platform; Teaching online

\section{Introduction}

The fifth generation mobile communication is one of the emerging technologies that change the face of engineering communication system.At present, the characteristics of $5 \mathrm{G}$, such as high speed, low delay and high reliability, provide better technical support for colleges and universities to carry out online live teaching.

The integration of 5G technology and teaching mode is not only the penetration of technology into the field of education, but also the inevitable trend of the development of technology and education, which is conducive to promoting the win-win situation of technology and education. The innovation of new teaching mode is not accidental, it is closely related to the progress of new media technology, the shortcomings of traditional teaching mode and the demand of teachers and students for teaching during the epidemic period. In the face of opportunities and challenges, it is imperative to examine the current situation of education and innovate the teaching mode.

\section{The background of $5 G$}

Thanks to the rapid development of information technology, Internet and other industries, as well as the crystallization of human wisdom. On June 6, 2019, the Ministry of industry and information technology issued 5G business license, marking that China has officially entered the $5 \mathrm{G}$ era.

At present, $5 \mathrm{G}$ wireless communication system is being promoted all over the world, and its goal is to provide all researchers, scholars and engineers with a real wireless world without existing communication system obstacles. As a new technology that can provide high speed, capacity, spectrum efficiency, energy efficiency and pseudo outdoor communication, 5G solves the problems in mobile communication system. At the same time, various industries, health departments and education departments have a huge demand for the use of the advantages of wireless communication. Such innovation has brought impetus to the Internet of things.

\section{Characteristics and advantages of $5 G$ Technology}

Till now, $5 \mathrm{G}$ is not defined, however, it may be the integration of several wireless techniques. Some of the Characteristics and advantages of $5 \mathrm{G}$ Technology are as follows ${ }^{[1]}$ :

Fast Internet speed: 100 times faster than previous 4 GLTE cellular networks.

High Capacity: In the age of $5 \mathrm{G}$, consumption in wireless traffific is expected to increase by $30 \%$; hence, $5 \mathrm{G}$ network should accommodate the increasing numbers of users with best quality of service ${ }^{[2]}$.

Break through the space limitation:5G technology can not only bring the ultimate experience of high speed, low delay and high reliability, but also more effectively realize the "interconnection of everything" to meet the rich and diverse application scenarios.

Full coverage: With the development of $5 \mathrm{G}$, the network coverage and data rate of indoor area are equivalent to the pseudo outdoor communication of outdoor area.

Undefined:5G is still an undefined standard, so the application of $5 \mathrm{G}$ technology in the future is open, because many innovations

Copyright (C) 2020 Yue Wu

doi: 10.18282/l-e.v9i4.1683

This is an open-access article distributed under the terms of the Creative Commons Attribution Non-Commercial License (http://creativecommons.org/licenses/by-nc/4.0/), which permits unrestricted non-commercial use, distribution, and reproduction in any medium, provided the original work is properly cited. 
of $5 \mathrm{G}$ are in progress.

At present, there is huge increasing demand from educational sectors to utilize the advantage of wireless communication. The key points of education informatization and network security in 2019 stressed that we should speed up the upgrading of educational informatization and actively promote the "Internet plus education", adhere to the high quality development, and support the education modernization with education informationization ${ }^{[3]}$. The development of $5 \mathrm{G}$ technology provides strong technical support for upgrading the educational informatization, and is conducive to the development of Internet plus education.

\section{The necessity of "5G mixed teaching mode"}

Blended teaching is a learning mode that combines online learning with traditional face-to-face teaching. In other words, in the teaching process, teachers should not only play a leading role in guiding students to think deeply, inspire and monitor the teaching process, but also fully reflect students' initiative, enthusiasm and creativity as the main body of the learning process. Through the organic combination of the two teaching organization forms, learners' learning will be led from shallow to deep to deep learning ${ }^{[4]}$.

Over the past 20 years, online education has grown rapidly in many countries. In a public report from Canada: at a tipping point, concludes that online education has reached its "tipping point": it has successfully become an integral part of higher education, and now it needs to shift its focus from providing university education to improving quality.

China's "key points of education informatization and network security in 2020" also emphasizes the establishment and improvement of an effective mechanism to expand the coverage of high-quality education resources by means of informatization, the development of fairer and higher quality education, and the development of accurate intelligence support under network conditions.

\section{The development of blended teaching mode}

With the advent of the Internet plus era, online education has developed rapidly. The mixed teaching mode has been welcomed by more and more scholars and teachers. At present, the mixed teaching mode mainly has the following forms. Mixed teaching mode based on MOOC; Hybrid teaching mode based on blue ink cloud class platform and "MOOC + SPOC + flipped classroom" mixed teaching mode.

But on the whole, these teaching modes have some problems, such as complex operation, lack of teaching interaction and teachers' guidance and communication in wisdom, emotion and values; lack of situational stimulation in the learning process, easy to produce attention fatigue and attention laxity; lack of standardized quality assurance measures, high drop out rate and low completion rate, insufficient evaluation and so on.

Driven by the innovation of " $5 \mathrm{G}+$ " mode, the function of online teaching mode is gradually improved, large-scale online learning is sought after by teachers and students, and the traditional education and teaching mode also changes, Only by making full use of "5G +" and artificial intelligence technology to build a new learning environment, reconstruct the teaching process, innovate the education and teaching mode, and carry out structural reform on the education system, can we really improve the quality of teaching and achieve the goal of cultivating innovative talents.

\section{Reflection and thinking}

Under the background of $5 \mathrm{G}$ era, how to make better use of $5 \mathrm{G}$ technology, promote the integration of $5 \mathrm{G}$ technology and teaching mode, and promote the development of hybrid teaching mode, is a problem worthy of reflection and thinking.

\subsection{Teachers should change their ideas.}

Teachers should change their ideas. They should abandon the traditional backward ideas.Aggressive and innovative. Promote the deep integration of the "5G "concept and the traditional educational concept.

\subsection{Elaborately designing online courses and sharing high quality educational resources}

In online teaching, teachers should promote self-regulated learning by task driving to cultivate students' autonomous learning ability; provide appropriate learning support to cultivate students' critical thinking ability; In view of the online and offline mixed teaching, starting from the curriculum quality standard, the school should carry out long-term special training to enhance teachers' curriculum design ability.

\subsection{Online learning should be further integrated with offline learning}

As the "5G "technology is widely used, teachers and students can use the network to choose the time and place of teaching and listening according to their own needs. Teachers should strengthen the cooperation between traditional teaching and network teaching, so that students can form a systematic framework for what they have learned, and deepen their mastery and understanding of knowledge.

\section{Conclusion}

In the " $5 \mathrm{G}+$ " era, it is the need of social development to carry out online and offline hybrid teaching mode. Only by cultivating talents with strong independent learning ability and practical ability, can we really meet the social needs and provide strong talent support for economic construction.

\section{References}

[1]Kumar Arun, Gupta Manisha. A review on activities of fifth generation mobile communication system[J]. Alexandria Engineering Journal,2018,57(2).

[2]ICT-317669 METIS Project, Scenarios, Requirement and KPIs for 5G Mobile and Wireless Communication System, <www. mettis.2020document.com>.

[3]The Key Points of Education Informatization and Network Security in 2019 was released [J]. China Education Network, 2019(04):6. 